\section{UČINCI TRENINGA BRZINE I AGILNOSTI KOD MLADIH NOGOMETAŠA}

\section{EFFECTS OF SPEED AND AGILITY TRAININGS AT YOUNG FOOTBALL PLAYERS}

\section{Vladimir Pokrajčić, Luka Herceg $^{1}$, Boris Dugonjić ${ }^{1} i$ Milenko Vojvodić 2}

${ }^{I}$ Sveučilište u Mostaru, Fakultet prirodoslovno-matematičkih $i$ odgojnih znanosti

${ }^{2}$ Univerzitet u Banjoj Luci, Fakultet fizičkog vaspitanja i sporta

Originalni naučni rad doi:10.5550/sgia.181401.se.phd UDK: 796.332.015.53

Primljeno: 24.05.2018. Odobreno: 08.06.2018.

Korespodencija: ass. Vladimir Pokrajčić Sveučilište u Mostaru, Fakultet prirodoslovno-matematičkih i odgojnih znanosti v.pokrajcic@gmail.com

Sportlogia 2018, 14 (1), 56-62. E-ISSN 1986-6119 napredak $u$ razvoju brzine, agilnosti $i$ eksplozivnosti kod mladih nogometaša. Istraživanje je provedeno na uzorku od 25

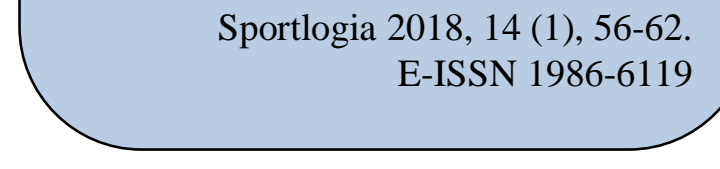

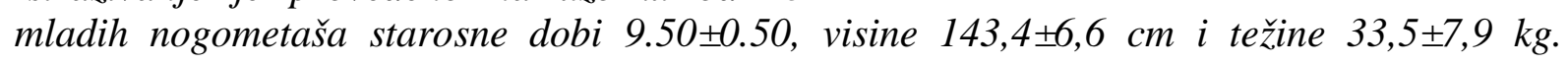
Ispitanici su članovi nogometnog kluba „NK Sloga“ iz Ljubuškog, koji treniraju u uzrasnoj kategoriji „Limači (U-11)“. Primijenjeno je ukupno 3 testa: 1. Trčanje na 20 metara iz visokog starta (Tr20m); 2. Trčanje naprijed-nazad s promjenom pod $90^{\circ}(\operatorname{TrNN}) ; 3$. Zig-zag trčanje između štapova (TrZZ). Analizom razlika (T-test) između inicijalnog $i$ finalnog mjerenja utvrđeno je poboljšanje rezultata. Prosječan rezultat inicijalnog mjerenja trčanja na $20 m$ iznosi 4,43 sekunde dok je prosječan rezultat finalnog mjerenja bolji za 10 stotinki $i$ iznosi 4,33 sekunde. U zig-zag testu prosječan rezultat inicijalnog mjerenja iznosio je 9,34 sekundi, dok je kod finalnog iznosio 9,1 sekundu. Prosječni rezultat popravio se za 0,24 stotinike. U trčanju s promjenom smjera $180^{\circ}$ ispitanici su prosječno trčali 14.37 sekundi u inicijalnom mjerenju, odnosno 14,08 sekundi u finalnom mjerenju. Prosječni rezultat popravio se za 0,29 stotinki. Korelacijskom analizom utvrđeno je da postoji statistički značajna povezanost između sva tri testa. Najveća povezanost između dva različita testa izmjerena je kod inicijalnog mjerenja testa trčanje s promjenom smjera za $180^{\circ}$ i finalnog mjerenja kod testa trčanje na 20 metara i iznosi 0,89.

Ključne riječi: trening, brzina, agilnost, mladi nogometaši

Pokrajčić, V., Herceg, L., \& Dugonjić, B., Vojvodić, M.(2018). Učinci treninga brzine i agilnosti kod mladih nogometaša. Sportlogia, 14 (1), 56-62. doi:10.5550/sgia.181401.se.phd 


\section{UVOD}

Nogomet predstavlja jednu od najpopularnijih sportskih igara današnjice. S obzirom na popularnost nogometa, zanimanje za tom vrstom aktivnosti nije izostalo ni kod djece $\mathrm{i}$ njihovih roditelja. Trening nogometa kod djece kompleksan je proces koji se bazira na usvajanju i provođenju specifičnih skupova kretnji i akcija nogometne igre, pa stoga i iziskuje poseban tretman njihova usavršavanja (Mršić i Jerković, 2010). Za uspjeh u nogometu potreban je velik broj sposobnosti, osobina i znanja od kojih su najvažnije antropološke karakteristike, specifične sposobnosti i znanja nogometaša te situacijska efikasnost i rezultati u natjecanju (Dujmović, Elsner i Fiorentini, 2000). Trening mlađih dobnih skupina treba biti okrenut motoričkom i psihičkom razvoju te motivaciji za fizičkom aktivnosti, a ne ranom očekivanju sportskih rezultata kod djece (Jukić, 2016) jer rana postignuća mogu ugroziti emocionalne, fizičke ili kreativne aspekte razvoja djeteta (Spock i Parker, 1998). U ovom istraživanju posvetili smo se razvoju brzine i agilnosti kod mladih nogometaša. U istraživanju koje su proveli Jozak, Segedi, Despot, Marčeić, Šoš i Ivanjko (2010), rezultati su pokazali da dolazi do značajnih promjena u testovima sprinta na $20 \mathrm{~m}$ i agilnosti 4 x 8 metara ponajprije zbog usavršavanja tehnike trčanja, opsegu treninga te razvoju koordinacije. Šamija (2011), utvrđuje promjene morfoloških karakteristika, motoričkih, i funkcionalnih sposobnosti nastalih pod utjecajem specifičnoga treninga brzine i agilnosti (SAQ) kod nogometaša juniorskog uzrasta te dolazi do rezultata koji pokazuju da je došlo do statistički značajnih promjena kod eksperimentalne skupine na svim varijablama, dok kod kontrolne skupine utvrđuje statistički značajne promjene na morfološkim varijablama, a na varijablama za procjenu agilnosti, eksplozivne snage tipa sprinta, fleksibilnosti te na varijabli za procjenu aerobne izdržljivosti utvrđuje vrlo mali pad ili stagnaciju procjenjivanih sposobnosti. Jukić (2016) istražuje razlike između selekcionirane i neselekcionirane skupine mladih nogometaša iste dobi u motoričkim znanjima i sposobnostima. Prema rezultatima, djeca u selekcioniranoj nogometnoj skupini i otvorenoj školi ne razlikuju se u motoričkim znanjima i sposobnostima osim u beep testu. Mnoga dosadašnja istraživanja su pokazala da ne postoji statistički značajna povezanost, to jest da su brzina i agilnost relativno nezavisni atributi kod profesionalnih nogometaša - Buttifant, Graham i Cross (2001), Little i Williams (2003), Sporiš, Milanović, Trajković i Joksimović (2011). Navedena istraživanja također pokazuju da osnovne vještine bez lopte imaju veću povezanost s brzinom, agilnosti i eksplozivnosti od vještina s loptom.

Pregledom literature uočljivo je kako dolazi do značajnih promjena u rezultatima testova za brzinu i agilnost, te da su brzina i agilnost relativno nisko povezani na uzorcima nogometaša seniora. Uz to, uočljiva je razlika u uspješnosti u izvedbi testova brzine i agilnosti s loptom i bez lopte. Većina dosadašnjih istraživanja se više posvetilo profesionalnim nogometašima ili starijim uzrastima i iz tog razloga je provedeno ovo istraživanje čiji je cilj utvrđivanje napretka u razvoju brzine $i$ agilnosti te utvrđivanje povezanosti između brzine i agilnosti kod mladih nogometaša starosne dobi $9,5 \pm 0,5$.

\section{METODE}

U ovom istraživanju uzorak ispitanika sačinjavalo je 25 mladih nogometaša starosne dobi $9,5 \pm 0,5$ godina, visine $143,4 \pm 6,6 \mathrm{~cm}$ i mase $33,5 \pm 7,9 \mathrm{~kg}$. Ispitanici su bili članovi nogometnog kluba „NK Sloga“ iz Ljubuškog, uzrasne kategorije „Limači (U-11)“. Trenirali su dva puta tjedno te su se vikendom natjecali u ,!Hej ligi U-11“. Nogometni staž igrača u klubu bio je od 1 do 3 godine. Eksperiment trenažnog postupka odvijao se dva puta tjedno kroz 8 tjedana, uz inicijalno i finalno mjerenje provedeno tjedan dana prije odnosno poslije tretmana. Treninzi su se odvijali na otvorenom, glavnom igralištu gradskog stadiona „Babovac“ u Ljubuškom sa prirodnom travom. Uz ostala pomagala (ljestve, čunjeve, štapove,

Pokrajčić, V., Herceg, L., \& Dugonjić, B., \& Vojvodić, M. (2018). Učinci treninga brzine i agilnosti kod mladih nogometaša. Sportlogia, 14 (1), 56-62. doi:10.5550/sgia.181401.se.phd 
krugove, prepone), ispitanici su trenirali sa loptom br. 4 (lakša i manjeg oblika od standarne veličine). Tretman se izvodio $u$ periodu od 17.10. do 18.12.2017. godine. Treninzi su se odvijali u poslijepodnevnom terminu od 14:00h. Trening je trajao cca. 60 min te se sastojao od tri dijela: uvodno-pripremni $(25 \mathrm{~min})$, glavni $(30 \mathrm{~min})$ i završni dio $(5-10 \mathrm{~min})$. Eksperimentalni tretmani se nisu izvodili čitav trening nego samo u uvodno - pripremnom dijelu treninga (20 minuta). Uzorak varijabli u ovom istraživanju dobiven je iz tri testa: $\operatorname{Tr} 20 \mathrm{~m}$ - trčanje na 20 metara iz visokog starta, TrZZ - zig-zag trčanje između štapova i Tr180 trčanje s promjenom smjera za $180^{\circ}$

Mjere morfoloških karakteristika (visina i težina) dobivene su primjenom osnovnog antropološkog instrumentarija (centimetarska vrpca i vaga). Testovi su snimljeni visokofrekventnom kamerom te su zatim analizirani i izmjereni u programu Kinovea. Vrijednosti su izražene stotinkama sekunde. Mjerenje je obavljeno na gradskom stadionu „Babovac“ u Ljubuškom. Rezultati istraživanja su obrađeni u programu Statistica 13. Za utvrđivanje deskriptivnih parametara inicijalnih i finalnih mjerenja korištena je deskriptivna statistika. Normalitet distribucije utvrđen je Kolmogorov - Smirnovljevim testom. Zavisni Ttest se koristio za utvrđivanje razlika između inicijalnog i finalnog mjerenja, dok je za utvrđivanje povezanosti između sva tri testa korištena korelacijska analiza.

\section{DISKUSIJA}

U tablici 1. prikazani su rezultati deskriptivne statistike rezultata inicijalnih i finalnih mjerenja postignutih u testovima $\operatorname{Tr} 20 \mathrm{~m}, \operatorname{Tr} Z Z$ i $\operatorname{Tr} 180^{\circ}$. Prosječan rezultat inicijalnog mjerenja testa Tr20m iznosi 4,43 sekunde dok je prosječan rezultat finalnog mjerenja bolji za 10 stotinki i iznosi 4,33. Rezultati su se kretali u rasponu od 3,9 do 4,92 sekundi u inicijanom mjerenju, odnosno 3,86 - 4,93 sekunde u finalnom mjerenju. Za rezultate testa $\operatorname{Tr} Z Z$ vidljivo je da se kreću u rasponu od 8,53 do 10,84 sekunde u inicijalnom mjerenju, odnosno $8-10,71$ sekunde $u$ finalnom mjerenju. Prosječan rezultat inicijalnog mjerenja iznosio je 9,34 a finalnog 9,1 sekundu. U testu $\operatorname{Tr} 180^{\circ}$ ispitanici su prosječno trčali 14.37 sekundi u inicijalnom mjerenju, odnosno 14,08 sekundi u finalnom mjerenju. Najbolji rezultat inicijalnog mjerenja iznosio je 12,76 sekundi, a finalnog 12,58, dok je najlošiji rezultat inicijalnog mjerenja iznosio 16,44 sekunde, a finalnog 16,21 sekundu. KS-testom smo utvrdili da distribucija ne odstupa značajno od normalne distribucije te smo pristupili daljnjoj obradi podataka.

Tablica 1. Deskriptivni parametri rezultata postignutih u inicijalnom i finalnom mjerenju $(N=25)$

\begin{tabular}{cccccc} 
Varijable & Mean & Min & Max & SD & MaxD \\
\hline Tr20m I & 4,43 & 3,9 & 4,92 & 0,27 & 0,120397 \\
Tr20m F & 4,33 & 3,86 & 4,93 & 0,28 & 0,139811 \\
TrZZ I & 9,34 & 8,53 & 10,84 & 0,63 & 0,135993 \\
TrZZ F & 9,1 & 8 & 10,71 & 0,63 & 0,124699 \\
$\operatorname{Tr} 180^{\circ} \mathrm{I}$ & 14,37 & 12,76 & 16,44 & 1,01 & 0,093553 \\
$\operatorname{Tr} 180^{\circ} \mathrm{F}$ & 14,08 & 12,58 & 16,21 & 0,92 & 0,098470 \\
\hline \hline
\end{tabular}

LEGENDA: Mean - aritmetička sredina; Min - minimalni rezultat; Max - maksimalni rezultat; SD - standardna devijacija; MaxD - normalitet distribucije

U tablici 2. prikazani su prosječni rezultati inicijalnog i finalnog mjerenja u testu Tr20m. Kod inicijalnog mjerenja prosječni rezultat iznosi 4,43 sekude, dok kod finalnog mjerenja rezultat iznosi 4,33 sekunde. U prosjeku, rezultat se popravio za 10 stotinki.

Pokrajčić, V., Herceg, L., \& Dugonjić, B., \& Vojvodić, M. (2018). Učinci treninga brzine i agilnosti kod mladih nogometaša. Sportlogia, 14 (1), 56-62. doi:10.5550/sgia.181401.se.phd 
Standarna devijacija iznosi 0,27 kod inicijalnog, 0,28 kod finalnog, što nam govori koliko u prosjeku elementi skupa odstupaju od rezultata aritmetičke sredine. Na osnovu pogreške koja je manja od 0,05, možemo tvrditi da postoje statistički značajne razlike između inicijalnog i finalnog mjerenja.

Tablica 2. T-test za zavisne uzorke za utvrđivanje razlika inicijalnih i finalnih mjerenja $u$ trčanju na $20 \mathrm{~m}$

\begin{tabular}{ccccc} 
Varijable & $\mathrm{N}$ & Mean & SD & $\mathrm{p}$ \\
\hline Tr20m I & 25 & 4,43 & 0,27 & \multirow{2}{*}{0,00} \\
Tr20m F & 25 & 4,33 & 0,28 & \\
\hline \hline
\end{tabular}

LEGENDA: $\mathrm{N}$ - broj ispitanika; Mean - aritmetička sredina; SD - standardna devijacija; $\mathrm{p}$

- razina značajnosti

U tablici 3. prikazani su prosječni rezultati inicijalnog i finalnog mjerenja testa $\operatorname{TrZZ}$. Kod inicijalnog mjerenja prosječni rezultat iznosi 9,34 sekunde, a u finalnom mjerenju 9,1 sekunda. Prosječni rezultat ovog testa popravio se za 0,24 stotinke. Standarna devijacija iznosi 0,63 kod oba mjerenja. Na osnovu pogreške koja je manja od 0,05, možemo tvrditi da postoje statistički značajne razlike između inicijalnog i finalnog mjerenja.

Tablica 3. T-test za zavisne uzorke za utvrđivanje razlika inicijalnih i finalnih mjerenja u zigzag trčanju

\begin{tabular}{ccccc} 
Varijable & $\mathrm{N}$ & Mean & SD & $\mathrm{p}$ \\
\hline TrZZ I & 25 & 9,34 & 0,63 & \multirow{2}{*}{0,00} \\
TrZZ F & 25 & 9,1 & 0,63 & \\
\hline \hline
\end{tabular}

LEGENDA: N - broj ispitanika; Mean - aritmetička sredina; SD - standardna devijacija; $\mathrm{p}$ - razina značajnosti

U tablici 4. prikazani su prosječni rezultati inicijalnog i finalnog mjerenja u testu $\operatorname{Tr} 180^{\circ}$. Prosječni rezultat inicijalnog mjerenja iznosio je 14,37 sekundi, dok je kod finalnog iznosio 14,08 sekundi. I tu bilježimo poboljšanje rezultata srednje vrijednosti za 0,29 stotinki. Standarna devijacija kod inicijalnog mjerenja iznosi 1,01, dok kod finalnog mjerenja iznosi 0,92 . Na osnovu pogreške koja je manja od 0,05 , možemo tvrditi da postoje statistički značajne razlike između inicijalnog i finalnog mjerenja.

Tablica 4. T-test za zavisne uzorke za utvrđivanje razlika inicijalnih i finalnih mjerenja $u$ trčanju s promjenom smjera za $180^{\circ}$

\begin{tabular}{ccccc} 
Varijable & $\mathrm{N}$ & Mean & SD & $\mathrm{p}$ \\
\hline $\operatorname{Tr} 180^{\circ} \mathrm{I}$ & 25 & 14,37 & 1,01 & 0,00 \\
$\operatorname{Tr} 180^{\circ} \mathrm{F}$ & 25 & 14,08 & 0,92 & \\
\hline \hline & & & & \\
LEGENDA: N - broj ispitanika; Mean & - aritmetička sredina; & SD - standardna devijacija; $\mathrm{p}$ \\
\hline \hline
\end{tabular}

Provedeni program polučio je napredak. Kako se radi o relativno kratkom vremenskom periodu, dobiveni napredak najvećim dijelom najvjerojatnije je rezultat bolje tehnike izvedbe. Naime, ispitanici su na svakom treningu vježbali mehaniku trčanja izvodeći pritom vježbe iz atletske škole trčanja koje su imale zadatak postići optimalnu

Pokrajčić, V., Herceg, L., \& Dugonjić, B., \& Vojvodić, M. (2018). Učinci treninga brzine i agilnosti kod mladih nogometaša. Sportlogia, 14 (1), 56-62. doi:10.5550/sgia.181401.se.phd 
duljinu i frekvenciju koraka. Napredak je također vidljiv i u promjenama smjera u testovima agilnosti.

Tablica 5. Korelacija između inicijalnih i finalnih mjerenja sva tri testa

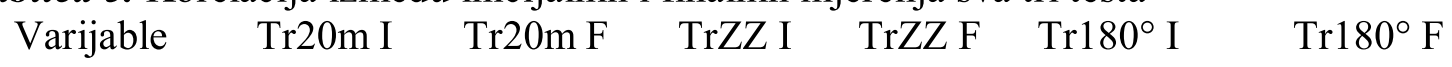

\begin{tabular}{ccccccc}
\hline $\operatorname{Tr} 20 \mathrm{~m} \mathrm{I}$ & 1,00 & 0,95 & 0,81 & 0,84 & 0,86 & 0,82 \\
\hline $\operatorname{Tr} 20 \mathrm{~m} \mathrm{~F}$ & 0,95 & 1,00 & 0,82 & 0,85 & 0,89 & 0,84 \\
\hline $\operatorname{TrZZ~I}$ & 0,81 & 0,82 & 1,00 & 0,96 & 0,86 & 0,84 \\
$\operatorname{TrZZ~F}$ & 0,84 & 0,85 & 0,96 & 1,00 & 0,87 & 0,85 \\
$\operatorname{Tr} 180^{\circ} \mathrm{I}$ & 0,86 & 0,89 & 0,86 & 0,87 & 1,00 & 0,98 \\
$\operatorname{Tr} 180^{\circ} \mathrm{F}$ & 0,82 & 0,84 & 0,84 & 0,85 & 0,98 & 1,00
\end{tabular}

Little i Williams (2003) analizirali su povezanosti između brzine trčanja i agilnosti (zig-zag test) na uzorku profesionalnih nogometaša. Dobivene su značajne ali i relativno niske povezanosti $(\mathrm{r}<0.70)$ između testova $(\mathrm{r}=0,45)$. Autori su stoga zaključili kako su brzina $\mathrm{i}$ agilnost relativno neovisnih kvaliteta $i$ da isti zahtijevaju specifična trenažna riješenja. Za razliku od navedenog istraživanja $u$ ovom radu su dobivene visoke povezanosti između testova (tablica 5). Povezanosti upućuju na to kako kod mlađih uzrasta ne postoji jasno razlikovanje sposobnosti, nego se uglavnom radi o univerzalno uspješnim pojedincima. Visoke povezanosti dobivene su između sva tri testa kako u inicijalnim tako i u finalnim mjerenjima. Inicijalno mjerenje testa $\operatorname{Tr} 180^{\circ}$ i finalno mjerenje testa $\operatorname{Tr} 20 \mathrm{~m}$ bilježi najveću povezanost od 0,89. Najmanju povezanost između dva različita testa čine inicijalna mjerenja testova $\operatorname{Tr} 20 \mathrm{~m}$ i $\operatorname{TrZZ}$ i iznosi 0,81 .

\section{ZAKLJUČAK}

Provedenim istraživanjem možemo zaključiti da su brzina i agilnost kod mladih nogometaša visoko povezane kvalitete. Stoga je za pretpostaviti kako će trening brzine imati značajan utjecaj na trening agilnosti i obratno. Visoke povezanosti upućuju na to kako kod mlađih uzrasta ne postoji jasno razlikovanje sposobnosti nego se uglavnom radi o univerzalno uspješnim pojedincima. Dobiveni rezultati nisu u skladu istraživanja na populaciji profesionalnih nogometaša gdje se $u$ pravilu dobivaju niske povezanosti između brzine $i$ agilnosti odnosno različitih agilnosti. Poboljšanje rezultata između inicijalnog i finalnog mjerenja ostvareno je na sva tri testa i ukazuje na to kako je trenažni postupak bio učinkovit. Međutim, ostaje nejasno koliko su ova poboljšanja rezultirala samim nogometnim treningom, a koliko dopunskim sadržajima kojima je razvijana brzina i agilnost. Ovaj podatak ostat će uskraćen zbog toga što u istraživanju nije bila uključena kontrolna skupina koja ne bi izvodila dopunske sadržaje nego samo nogometni trening. Vjerojatan razlog značajnog poboljšanja $u$ sva tri testa leži u činjenici da brzina i agilnost imaju slične karakteristike. Osnovu obučavanja metodike treninga brzine i agilnosti čini učenje tehnike hodanja, trčanja, promjene smjera kretanja, ekonomičnosti kretanja i sl. S obzirom da je senzitivna faza razvoja brzine i agilnosti kod dječaka i djevojčica između 7. i 11. godine, vidljivo je zašto su rezultati inicijalnog i finalnog mjerenja značajno poboljšani. S obzirom da se nisu ranije susretali s ovakvim načinom testiranja, ispitanici su najvjerojatnije napredovali u tehnici odnosno ekonomičnosti trčanja. Trening mladih sportaša mora biti promatran kao dugoročan plan kojim se povećanje opterećenja i ukupni tjelesni, tehničko-taktički i mentalni zahtjevi primjenjuju postupno tijekom faza rasta i razvoja. Temelje treninga tijekom djetinjstva treba postaviti putem višestranog razvoja, a ne pomoću uskog sportskog-specifičnog treninga, što će dati mladom sportašu bolje osnove za vrhunsku izvedbu.

Pokrajčić, V., Herceg, L., \& Dugonjić, B., \& Vojvodić, M. (2018). Učinci treninga brzine i agilnosti kod mladih nogometaša. Sportlogia, 14 (1), 56-62. doi:10.5550/sgia.181401.se.phd 


\section{LITERATURA}

Buttifant, D., Graham, K., \& Cross, K. (2001). 55 Agility and speed in soccer players are two different performance parameters. Science and football IV, 4, 329.

Dujmović, P., Elsner, B., \& Fiorentini, F. (2000). Škola nogometa. Zagrebački nogometni savez.

Jozak, R., Segedi, I., Despot, T., Marčeić, Z., Šoš, K., \& Ivanjko, A. (2010). Strength and conditioning training in soccer school Dinamo Zagreb. In I. Jukić, C. Gregov, S. Šalaj, L. Milanović i T. Troš-Bobić (Eds.), 8. godišnja međunarodna konferencija Kondicijska priprema sportaša 2010 (pp. 105-112). Zagreb, HR. Udruga kondicionih trenera Hrvatske i Kineziološki fakultet, Sveučilište u Zagrebu.

Jukić, I. (2016). Razlike $u$ motoričkim znanjima $i$ sposobnostima između selekcionirane $i$ neselekcionirane skupine djece u nogometu. Zagreb, RH: Kineziološki fakultet Sveučilišta u Zagrebu.

Little, T., \& Williams, A. (2003). Specificity of acceleration, maximum speed and agility in professional soccer players, Journal of Strength and Conditioning Research, 19(1), 76-78.

https://doi.org/10.1519/00124278-200502000-00013

https://doi.org/10.1519/14253.1

PMid:15705049

Mršić, A. \& Jerković, S. (2010.) Nogometni priručnik 3. Đakovo, RH: Andro Mršić.

Spock, B., \& Parker, S. (1998). Dr. Spock's Baby and Child Care. New York City, USA: Pocket Books.

Sporiš, G., Milanović, Z., Trajković, N., \& Joksimović, A. (2011). Correlation between speed, agility and quickness (SAQ) in elite young soccer players. Acta kinesiologica, 5(2), 36-41.

Šamija, K. (2011). Učinci specifičnog treninga brzine $i$ agilnosti (SAQ) na morfološka, motorička i funkcionalna obilježja nogometaša. Doktorska disertacija. Kineziološki fakultet, Sveučilišta u Zagrebu. 


\begin{abstract}
The goal of this research is to determine the progress in development of speed, agility and explosiveness in young footballers. The research was conducted on a sample of 25 young footballers aged $9.50 \pm 0.50$, height $143,4 \pm 6,6 \mathrm{~cm}$ and weight $33,5 \pm 7,9 \mathrm{~kg}$. The respondents are members of the football club "NK Sloga" from Ljubuski, who are trained in the age category "Limaci (U-11)". A total of 3 tests were applied: 1. Running at 20 meters from the high start (Tr20m); 2. Running back and forth with a change of $90^{\circ}(\operatorname{TrNN}) ; 3$. Zig-zag running between poles (TrZZ). An analysis of the differences (T-test) between initial and final measurements resulted in an improvement in the results. The average result of the initial $20 \mathrm{~m}$ run measurement is 4,43 seconds while the average result of the final measurement is better for 10 hundredths and is 4,33 seconds. In the zig-zag test, the average score of the initial measurement was 9,34 seconds, while the final result was 9,1 seconds. The average score was improved by 0,24 hundredths. In a $180^{\circ}$ shift running, respondents ran averaged 14.37 seconds in the initial measurement, or 14,08 seconds in the final measurement.The average score improved by 0,29 hundredths. Correlation analysis found that there was a statistically significant connection between all three tests. The highest connection between the two different tests was measured at the initial measurement of the run test with $180^{\circ}$ change of direction and the final measurement at the 20m running test and it was 0,89.
\end{abstract}

Keywords: training, speed, agility, young football players

Primljeno: 24.05.2018. Odobreno: 08.06.2018.

Korespodencija: ass. Vladimir Pokrajčić Sveučilište u Mostaru, Fakultet prirodoslovno-matematičkih i odgojnih znanosti v.pokrajcic@gmail.com

Pokrajčić, V., Herceg, L., \& Dugonjić, B., \& Vojvodić, M. (2018). Učinci treninga brzine i agilnosti kod mladih nogometaša. Sportlogia, 14 (1), 56-62. doi:10.5550/sgia.181401.se.phd 